\title{
“Otimização da extração de própolis em solução aquosa e caracterização do extrato"
}

Costa, Denis Jansen Lemos. Otimização da extração de própolis em solução aquosa e caracterização do extrato. 2020. 81p. Dissertação (Mestrado) - Faculdade de Filosofia, Ciências e Letras de Ribeirão Preto, Universidade de São Paulo, Ribeirão Preto, 2020.

\begin{abstract}
RESUMO
A própolis é uma substância resinosa com importante conteúdo de compostos bioativos e ceras que protegem a colmeia contra fungos, bactérias e insetos. Para o uso da própolis como remédio terapéutico é necessário realizar uma extração etanólica, na qual é removida parte de sua cera e preservado seus polifenóis. Entretanto, existe uma limitação no consumo desse extrato devido à concentração de álcool nele presente. Portanto, este trabalho tem como objetivo desenvolver a extração de própolis em meio aquoso para o uso comercial. Para isso, a própolis in natura foi moída em liquidificador e peneirada usando peneiras de 35 Mesh, 45 Mesh, 80 Mesh e 100 Mesh, as quais foram caracterizadas. Assim, foram determinados o tamanho de partículas, os parâmetros de cor das frações, a umidade, cinzas, teor de ceras, atividade antioxidante, teor de compostos fenólicos totais e flavonoides das frações de própolis. Os extratos etanólicos das frações de menor tamanho de partícula (Frações A e B) apresentaram menor teor de compostos fenólicos (A: 2,86 mg/mL) e menor teor de cera (B: 3,39\%). Por outro lado, a fração com maior tamanho de partícula (G) apresentou maior teor de compostos fenólicos $(5,35 \mathrm{mg} / \mathrm{mL})$, flavonoides e atividade antioxidante. Assim, o processo de moagem e peneiragem permitiu a separação das ceras da própolis, mas também provocou perdas de compostos bioativos. Na etapa seguinte do trabalho, foi realizada a otimização do processo de extração aquosa da própolis através de um Delineamento Central Composto Rotacional (DCCR) $2^{3}$, que permitiu avaliar o efeito do tamanho de partícula, tempo de extração e concentração de álcali sobre o pH, massa mecânica, teor de sólidos solúveis, teor de compostos fenólicos e teor de flavonoides do extrato. A concentração de álcali demonstrou ser a variável com maior influência sobre o extrato, enquanto o tamanho de partícula não teve influência significativa sobre os parâmetros avaliados. A metodologia de superfície de resposta permitiu otimizar as condições para a preparação do extrato aquoso de própolis. $\mathrm{O}$ extrato otimizado apresentou alto rendimento de extração (sólidos solúveis: $11,8 \%$ e massa mecânica: $33,1 \%$ ), alto teor de compostos bioativos (Teor de flavonoides: 4,3mg/mL e teor de compostos fenólicos: $19,8 \mathrm{mg} / \mathrm{mL}$ ) e atividade contra o crescimento do microorganismo S. Aureus.
\end{abstract}

PALAVRAS CHAVE: própolis, extração, cera, flavonoides, compostos fenólicos, atividade antioxidante. 
Costa, Denis Jansen Lemos. Optimization of propolis extraction in aqueous solution and characterization of the extract. 2020. 81p. Dissertação (Mestrado) - Faculdade de Filosofia, Ciências e Letras de Ribeirão Preto, Universidade de São Paulo, Ribeirão Preto, 2020.

\begin{abstract}
Propolis is a resinous substance with an important content of bioactive compounds and beewax. It protects the hive against fungi, bacteria and insects. An ethanol extraction must be conducted for propolis to be used as a therapeutic drug. During this extraction, part of the beewax is removed, while the polyphenols are preserved. However, the consumption of this extract is limited due to the concentration of alcohol that it contains. This work aims to develop the extraction of propolis in aqueous solution for commercial use. For this purpose, propolis in natura was ground in a blender, sieved through 35mesh, 45-mesh, 80-mesh, and 100- mesh sieves, and characterized after this. Then, particle size, color parameters of the fractions, moisture, ash, beewax content, antioxidant activity, and total phenolics and flavonoids in the propolis fractions were determined. The ethanolic extracts of the fractions with the smallest particle size (Fractions A and B) had lower content of phenolic compounds (A: $2.86 \mathrm{mg} / \mathrm{mL}$ ) and beewax (B: 3.39\%). On the other hand, the fraction with the largest particle size $(\mathrm{G})$ had higher content of phenolic compounds $(5.35 \mathrm{mg} / \mathrm{mL})$, flavonoids, and antioxidant activity. Thus, the grinding and screening processes allowed beewax to be separated from propolis, but it also caused loss of bioactive compounds. In the next step, the aqueous extraction process was optimized for propolis through a Central Rotational Compound Design $2^{3}$, which allowed particle size, extraction time and alkali concentration effects on $\mathrm{pH}$, mechanical mass, soluble solids content, phenolic compounds content, and flavonoids content in the extract to be evaluated. The alkali concentration was the variable that influenced the extract the most, while particle size did not affect the evaluated parameters significantly. The response surface methodology allowed us to optimize the conditions for the preparation of the aqueous propolis extract. The optimized extract showed high extraction yield (soluble solids: $11.8 \%$ and mechanical mass: $33.1 \%$ ), high content of bioactive compounds (Flavonoida content: $4.3 \mathrm{mg} / \mathrm{mL}$ and Phenolics content: $19.8 \mathrm{mg} / \mathrm{mL}$ ), and biological activity against the growth of the $S$. Aureus pathogen.
\end{abstract}

KEYWORDS: propolis, extraction, beewax, flavonoids, phenolic compounds, antioxidant activity. 


\section{INTRODUÇÃO}

A própolis é uma substância resinosa de composição complexa sintetizada pelas abelhas a partir dos mais diversos produtos coletados em brotos de árvores, resinas, mucilagens, treliças e outras fontes vegetais (MONROY, 2017; ANDRADE, 2017).

Essa substância é alterada pelas enzimas contidas na saliva das abelhas e utilizada para cobrir as entradas na colmeia a fim de protegê-la contra fungos, bactérias e insetos (BERROUKCHE et al., 2017). É comum encontrar nas colmeias pequenos animais ou parte deles envoltos em própolis, em perfeito estado de conservação, devido à ação antimicrobiana da própolis, o que impede a decomposição do cadáver (PEREIRA, 2008).

A composição da própolis depende do tipo de planta, das resinas e das espécies de abelhas. Portanto é um produto que pode variar de composição segundo a fonte de origem. Em geral é composta por 50\% de resina e bálsamo vegetal; 30\% de cera; $10 \%$ de óleos essenciais e aromáticos; $5 \%$ de pólen e 5\% de outras substâncias variadas, incluindo também restos orgânicos. É considerada uma das misturas mais heterogêneas encontradas em fontes naturais (PARK et al., 2002; LUSTOSA et al., 2008; MATSUDA, 2006).

Existem diferentes tipos de própolis cujas características diferem quanto a sua origem botânica e espécie de abelha produtora. Só no Brasil foram identificados 12 tipos, sendo cinco delas encontradas na região Sul, uma na região Sudeste e seis no Nordeste, entre elas a própolis Verde, a própolis Marrom, a própolis Vermelha, a própolis Amarela, a própolis Preta e a geoprópolis. A principal fonte da própolis encontrada na região sudeste é Baccharis dracunculifolia (alecrim do campo), Hyptis divaricata e Dalbergia ecastophyllum (Rabo-de-bugio) são as principaisfontes da própolis nordestina e Populus nigra (álamo) é a principal fonte de resina da própolis encontrada na região Sul do Brasil.

A própolis Verde, exclusiva do sudeste brasileiro, popularizou-se no Brasil e no exterior por fortalecer o sistema imunológico e apresentar eficiência no combate de diversas doenças. Grande parte da própolis verde produzida no Brasil é exportada para diversas regiões do mundo, principalmente para a China e o Japão, para consumo e estudo.

A própolis Marrom, também conhecida como tradicional ou própolis comum é encontrada e produzida em todas as regiões do Brasil. Sua origem botânica diverge de acordo com a região em que é produzida e sua coloração pode variar entre marrom claro 
e marrom esverdeado (ANDRADE et al., 2017). Sua coloração mais escura é causada, na maioria das vezes, por sua exposição a luz e ao calor que causa sua oxidação e também perda de grande parte de seus compostos voláteis, dentre eles, os responsáveis pela atividade biológica no corpo humano. Esta variedade de própolis, embora seja abundante em todo o Brasil, possui uma menor atividade biológica quando comparada a própolis verde e a própolis vermelha.

A própolis in natura precisa passar por um processo de purificação para ser utilizada. Nesse processo é removido sua cera e preservado seus polifenóis. A técnica mais popular de obtenção do extrato de própolis é a extração alcóolica devido à alta solubilidade de seus polifenóis em etanol (ANDRADE et al., 2017). A extração aquosa é pouca explorada e conhecida.

Considerando a própolis como uma substância natural rica em componentes benéficos à saúde humana e pouco explorada na forma de extrato aquoso, este trabalho justifica-se pelo estudo e otimização do processo de extração aquosa dos compostos bioativos presentes na própolis in natura, o qual pode permitir sua aplicação industrial e desenvolvimento de um produto comercial.

\section{CONCLUSÃO}

Conclui-se que o processo de moagem e peneiragem favoreceu a remoção de parte da cera da própolis, melhorando o processo de obtenção do extrato, mas também ocasionou perda de compostos bioativos, principalmente dos compostos fenólicos totais.

As frações mais grossas apresentaram um maior rendimento de extração e melhor qualidade do extrato: maior atividade antioxidante, maior teor de compostos fenólicos e maior teor de flavonoides. Isso pode ser justificado pelo fato de possuírem maior teor de ceras, as quais podem ajudar a proteger os compostos bioativos de processos oxidativos por contato com a luz. As frações mais grossas também apresentaram uma coloração mais escura que indicaria a presença de compostos fenólicos, resultando em maior atividade antioxidante destas frações.

O extrato aquoso em meio alcalino obtido neste trabalho apresentou composição e propriedades semelhantes ao extrato etanólico comercial, o que confirma a eficiência do processo de extração utilizado e também a segurança do produto final por não conter 
microrganismos. O extrato aquoso otimizado, obtido com a própolis moída não peneirada $(\mathrm{N})$, concentração álcali 14,2 mg/mL e tempo de extração de 12 horas, apresentou maior teor de compostos fenólicos e flavonóides do que o extrato etanólico comercial.

Os modelos matemáticos obtidos para a massa mecânica, extrato solúvel e teor de compostos fenólicos usando a metodologia de superfície de resposta demonstrou ser eficiente e confiável, uma vez que foram produzidos extratos com alto teor de compostos bioativos e com atividade antioxidante. Os extratos aquosos apresentaram estabilidade e ausência de contaminação microbiológica durante 30 dias desde sua produção.

Também foi verificado que o extrato aquoso da própolis verde, de origem brasileira, obtida neste trabalho, possui atividade contra a bactéria Gram-positiva Staphylococcus aureus apresentando atividade antimicrobiana comparável com o extrato etanólico comercial.

\section{REFERÊNCIAS BIBLIOGRÁFICAS}

ANDRADE, J. K. S. et al. Evaluation of bioactive compouns potential and antioxidant activity of brown, green and red propolis from Brazilian northeast region. Food Research International, São Cristóvão, n. 101, p. 129-138, aug, 2017.

BANKOVA, V. et al. Chemical composition of European propolis: expected and unexpected results. ZeitschriftfürNaturforschung C, v. 57, n. 5-6, p. 530-533, 2002.

BERROUKCHE, A. et al. Characterization of bioactive compounds in SouthWestern Algeria propolis samples. Journal of New Technology and Materials, Algeria, v. 07, n. 02, p. 67-71, dec, 2017.

CABRAL, I. S. R. et al. Composição fenólica, atividade antibacteriana e antioxidante da propolis vermelha brasileira. Quim. Nova 32, 1523-1527, 2009. 
ÇELEMLI, Ö. G. et al. More insight into the chemical composition of Greek propolis; differences and similarities with Turkish propolis. ZeitschriftfürNaturforschung C, v. 68, n. 11-12, p. 429-438, 2013.

COELHO, Joana Patrícia Mendes. Identificação e quantificação de compostos fenólicos em própolis da região sul do Brasil. Avaliação da atividade antioxidante por técnicas espectroscópicas e eletroquímicas. 2013. Tese de Doutorado.

DAUGSCH, Andreas et al. A própolis vermelha do nordeste do Brasil e suas características químicas e biológicas,p. 144, 2007.Dissertação de mestrado.

DURAN, N. et al. GC-MS analysis and antileishmanial activities of two Turkish propolis types. Parasitologyresearch, v. 108, n. 1, p. 95-105, 2011.

Estudo sobre a própolis vermelha. Disponível em: < http://sebraepb.livreforum.com/t6-estudo-sobre-a-propolis-vermelha>. Acesso em: 17 de janeiro de 2018.

FALCÃO, S. I. et al. Phenolic characterization of Northeast Portuguese propolis: usual and unusual compounds. Analytical and bioanalytical chemistry, v. 396, n. 2, p. 887-897, 2010.

FRANCISCO, L. et al. Evaluation of radical scavening activity, intestinal cell viability and antifungal activity of Brasilianpropolis by-product. Food Research International, Porto, n. 105, p. 537-547, nov, 2017.

FROZZA, C. O. S. et al. Chemical characterization, antioxidant and cytotoxic activities of Brazilian red propolis.Food and Chemical Toxicology, 52, 137-142, 2012.

GIAMPIERI, F. et al. Are by-products from beeswax recycling process a new promising source of bioactive compounds with biomedicinal properties? Food and Chemical Toxicology, Ancona, n. 112, p. 126-133, dec, 2017. 
JAFARI, N. J. et al. The effect of chitosan coating incorporated with ethanolic extract of propolis on the quality of refrigerated chicken fillet. Journal of Food Processing and Preservation. 2017;00:e13336.

LU, L.; CHEN, Y.; CHOU, C. Antibacterial activity of propolis agains Staphylococcus aureus. International Journal of Food Microbiology, 102, p213-220, 2005.

MACHADO, B. A. S. et al. Chemical Composition and Biological Activity of Extracts Obtained by Supercritical Extraction and Ethanolic Extraction of Brown, Green and Red Propolis Derived from Different Geographic Regions in Brazil. 2016. PLOS ONE 11(1): e0145954.

MONROY, Y. M. et al. Brazilian green própolis extracts obtained by conventional processes and by process at high pressure with supercritical carbono dioxide, ethanol and water. JournalofSupercritcalFluids, Campinas, n. 130, p. 189-197, aug, 2017.

MORAES, C. S. Isolamento e identificação de formononetina da própolis de João Pessoa-PB, estudo de sua sazonalidade e avaliação de suas atividades biológicas. Universidade Estadual de Campinas, Campinas, 2009.

PARK, Y.K.; ALENCAR S. M.; AGUIAR C.L. Botanical origin and chemical composition of Brazilian propolis. J Agric Food Chem 2002;50:2502-6.

PEREIRA, D.A. Extração aquosa de própolis e secagem em leito de espuma para uso em alimentos. 2008. 88f. Dissertação de mestrado. Engenharia de Alimentos da Universidade Estadual do Sudoeste da Bahia, UESB, Itapetinga, 2008.

PICCINELLI, A. L. et al. Chemical composition and antioxidant activity of Algerian propolis. Journal of agricultural and food chemistry, v. 61, n. 21, p. 50805088, 2013. 
POPOVA, M. P. et al. GC-MS profiling of diterpene compounds in Mediterranean propolis from Greece. Journal of agricultural and food chemistry, v. 58, n. 5, p. 3167$3176,2010$.

DAVEY, R. W.; GRANGE, J. M. Antibacterial properties of propolis (bee glue). J. R. Soc. Med., 83, p159-161, 1990.

RUFINO, M. S. M. et al. Metodologia científica: determinação da atividade antioxidante total em frutas pela captura do radical livre ABTS. Fortaleza: Embrapa Agroindústria Tropical, 2007.(Comunicado técnico, 128). e-ISSN 1983-4063-www. agro. ufg. br/pat-Pesq. Agropec. Trop., Goiânia, v. 44, n. 4. out./dez, p. 399-408, 2014.

SILICI, S.; ÜNLÜ, M.; VARDAR-ÜNLÜ, G. Antibacterial activity and phytochemical evidence for the plant origin of Turkish propolis from different regions. World Journal of Microbiology and Biotechnology, v. 23, n. 12, p. 1797-1803, 2007.

SPULBER, R. et al. Chemical diversity of polyphenols from bee pollen and propolis. AgroLife Scientific Journal, Bucharest, v. 6, n. 2, p. 183-194, 2017.

SCHIMDT, E. M. et al. Determinação do teor de fenólicos e flavonóides totais em extratos de própolis. Disponível em <http://www.unicentro.br/pesquisa/anais/proic/2007/pdf/artigo_50.pdf>. Acesso em: 17 de janeiro de 2018.

SILVA, M. P. Análises físico-químicas de produtos apícolas para fins de controle de qualidade. 2013. 63f. Trabalho de estágio. Instituto de Biociências, Unesp, Rio Claro, 2013.

SOUZA, C. M. M. et al. Fenóis totais e atividade antioxidante de cinco plantas medicinais. Química Nova, São Paulo, v. 30, n. 2. 2007. Disponível em: <http://www.scielo.br/scielo.php?script=sci_arttext\&pid=S0100-40422007000200021> . Acesso em: 17 de janeiro de 2018. 
TAPIA, E. V. Identificação da fonte botânica, caracterização química e avaliação das atividades biológicas das própolis coletadas no Peru.2017. 142f. Tese de doutorado. Faculdade de Engenharia de Alimentos. Universidade Estadual de Campinas, Campinas, 2017.

ZABAIOU, N. et al. Biological properties of própolis extracts: Something new from an ancient product. Chemistry and Physics of Lipids, Clermont-Ferrand, n. 207, p. 214-222, jul, 2017.

ZANCANELA, D. C. et al. Physical, chemical and antimicrobial implications of the association of propolis with a natural rubber latex membrane. Materials Letters, São Paulo, n. 209, p. 39-42, apr, 2017.

Y. K. Park et al. Antimicrobial activity of própolis on oral microorganisms. Curr. Microbiol., 36, p24-28, 1998. 